\title{
A CHEMICAL PROCESS FOR PREPARING CELLULOSIC FIBERS HIERARCHICALLY FROM KENAF BAST FIBERS
}

\author{
Jinshu Shi, ${ }^{a}$ Sheldon Q. Shi ${ }^{\mathrm{a}, *}$ H. Michael Barnes, ${ }^{\mathrm{b}}$ and Charles U. Pittman, Jr. ${ }^{\mathrm{c}}$
}

\begin{abstract}
The objective of this research was to evaluate an all-chemical process to prepare nano-scale to macro-scale cellulosic fibers from kenaf bast fibers, for polymer composite reinforcement. The procedure used in this all-chemical process included alkaline retting to obtain single cellulosic retted fiber, bleaching treatment to obtain delignified bleached fiber, and acidic hydrolysis to obtain both pure-cellulose microfiber and cellulose nanowhisker (CNW). At each step of this chemical process, the resultant fibers were characterized for crystallinity using X-ray diffraction (XRD), for functional groups using the Fourier Transform Infrared spectroscopy (FTIR), and for surface morphology using both the scanning electron microscopy (SEM) and transmission electron microscopy (TEM). The chemical components of the different scale fibers were analyzed. Based on the raw kenaf bast fibers, the yields of retted fibers and bleached fibers were $44.6 \%$ and $41.4 \%$. The yield of the pure cellulose microfibers was $26.3 \%$. The yield of CNWs was $10.4 \%$, where about $22.6 \%$ acellulose had been converted into CNWs. The fiber crystallinity increased as the scale of the fiber decreased, from $49.9 \%$ (retted single fibers) to $83.9 \%$ (CNWs). The CNWs had fiber lengths of $100 \mathrm{~nm}$ to $1400 \mathrm{~nm}$, diameters of 7 to $84 \mathrm{~nm}$, and aspect ratios of 10 to 50 . The incorporation of $9 \%$ (wt\%) CNWs in polyvinyl alcohol (PVA) composites increased the tensile strength by $46 \%$.
\end{abstract}

Keywords: Kenaf bast fiber; Cellulose nanowhisker; Retted fiber; Bleached fiber; Microfiber; Composites

Contact information: a: Department of Forest Products, Mississippi State University, P.O. Box 9820, Starkville, MS 39762-9820 USA; b: Department of Forest Products, Mississippi State University, P.O. Box 9820, Starkville, MS 39762-9820 USA; c: Department of Chemistry, Mississippi State University, P.O. Box 9573, Starkville, MS 39762-9573 USA; *Correspondingauthor: sshi@cfr.msstate.edu

\section{INTRODUCTION}

Natural fibers used to reinforce the polymer composites are in a form of a single cellulosic fiber or fiber bundles obtained from wood or agricultural plants through a retting process. These processes include chemical, mechanical, and bio-retting. Kenaf bast fiber is a promising reinforcement element for polymer composites because of its high cellulose content and fast rate of growth. The cellulosic fibers are cellulose chains composed of amorphous regions and crystalline regions, together with some lignin and hemicelluloses. Removing the hemicelluloses and lignin, and reducing the amorphous regions can effectively increase the cellulose content and the percentage of crystalline regions of the cellulosic fibers, so that the fibers will have a much higher strength. Zadorecki and Michell (1989) reported that the elastic moduli of solid wood, single pulp fiber, microfibrils, and crystallites were $10 \mathrm{GPa}, 40 \mathrm{GPa}, 70 \mathrm{GPa}$, and $250 \mathrm{GPa}$, 
respectively. Thus, breaking down the cellulosic fiber to the micro or nano scale improves the strength of the resulting fibers significantly.

Cellulose nanofibers have been prepared from different resources, such as cotton linter (Roohani et al. 2008 ), flax bast fiber (Bhatnagar and Sain 2005; Qua 2009), hemp fiber (Bhatnagar and Sain 2005), kraft pulp (Bhatnagar and Sain 2005; Lu et al. 2008), rutabaga (Bhatnagar and Sain 2005), and microcrystalline cellulose (Lee et al. 2009). Technologies to prepare cellulose nanofibers have been reported, including an enzymic method (Henriksson et al. 2007), a bacterial method (Tsuchida and Yoshinaga 1997), cryocrushing (Chakraborty et al. 2005), a grinding treatment (Iwamoto et al. 2005), and an ultrasonic technique (Wang et al. 2006). All these methods require using a combination of chemical, mechanical and other processes in order to prepare cellulose nanofibers from raw natural fibers. The resultant cellulose nanofibers had different morphologies, such as entangled network or rod-like nanoparticles. Different terminalogies have been used to designate the rod-like "nanoparticles" or "nanofibers", e.g. nanowhiskers, monocrystals, nanocrystals, etc. (Siqueira et al. 2009). In this study, we use the term "cellulose nanowhiskers" (CNW).

The objective of this study was to evaluate an all-chemical process to extract cellulosic fibers ranging from macro scale to nano scale from kenaf bast fibers. Nanoand microfibers could be reinforcement candidates for polymer composites. The retted fibers, bleached fibers, microfibers, and CNWs were obtained and characterized. CNWreinforced polyvinyl alcohol (PVA) composites were fabricated, and the tensile properties of these CNW/PVA composites were evaluated. The reason for using PVA as the matrix is because that it is water soluble, allowing the film casting process to be applied.

\section{EXPERIMENTAL}

\section{Materials}

Kenaf bast fibers obtained from the Mississippi State University (MSU) North Farm were used as the raw material. Sodium hydroxide beads (laboratory grade) were used to prepare a 5\% aqueous solution. Glacial acetic acid was used to neutralize the $\mathrm{pH}$ of the alkaline retting system. Technical grade aqueous hydrogen peroxide $(37 \%)$ solution and sulfuric acid (98\%) solutions were diluted to $10 \%$ and $30 \%$, respectively. Polyvinyl alcohol (PVA) (MW=100,000) powder (Fisher Scientific) was used to fabricate the composites.

\section{Methods}

Preparation of $\mathrm{CNWS}$

The kenaf bast fibers with a moisture content of $11 \%$ were retted in a $5 \% \mathrm{NaOH}$ solution at $160{ }^{\circ} \mathrm{C}$ for one hour. A sealed reactor was used, in which the alkaline liquid reached its autogeneous vapor pressure. Then the $\mathrm{pH}$ value of the retting liquid and the retted fibers was adjusted to 7.0 using acetic acid, and the retted fibers were washed with water to remove the chemicals from the fibers. The retted fibers were then bleached with $10 \% \mathrm{H}_{2} \mathrm{O}_{2}$ at $70{ }^{\circ} \mathrm{C}$ for 1 hour in order to remove the remaining lignin. Acid hydrolysis of 
the bleached fibers was then conducted with $30 \% \mathrm{H}_{2} \mathrm{SO}_{4}$ at $80^{\circ} \mathrm{C}$ with mechanical stirring for four hours. An acidic suspension of microfibers and CNWs was obtained from the acid hydrolysis. The acid was removed by centrifugation using an Eppendorf Centrifuge (Model 5810) at a rotating speed of 6,500 rpm for five minutes. The microfibers and CNWs were both precipitated and could not be separated until the $\mathrm{pH}$ value of the suspension became around 6.0. The supernatant acidic liquid was removed, and fresh distilled water was added to dilute the remnant acid. The process was repeated until the suspension was neutralized. The suspension was put into a centrifuge with a rotation speed of 7,600 rpm. CNWs were separated from the microfiber sediments. The milk-like supernatant in the $\mathrm{CNW}$ suspension was removed. The separation was repeated until the supernatant liquid was clear. However, it is still unknown why CNWs and microfibers could not be separated in acidic aqueous suspension. The CNW suspension was sonicated to disrupt the of nanowhisker aggregates for ten minutes using a Cole-Parmer ultrasonic processor with a CV33 converter and a $13 \mathrm{~mm}$ probe $(750$ watts, $20 \mathrm{kHz}, 40 \%$ amplitude of vibration). The samples of retted fibers, bleached fibers, microfibers, and $\mathrm{CNW}$ sere freeze-dried before characterization. The yields were obtained as the ratio of the oven-dry weights of the resultant fibers to the original weight of raw kenaf bast fiber.

\section{CNW/PVA composites fabrication}

PVA aqueous solutions were mixed with CNW aqueous suspensions followed by ultrasonic treatment for 5 min ( 750 watts, $20 \mathrm{kHz}, 40 \%$ amplitude of vibration) in order to homogenize the distribution of CNWs in the mixtures. The weight ratios of CNW to PVA were controlled at 3:97 and 9:91, respectively. CNW/PVA composite films, with the CNWs loading of $3 \%$ and $9 \%$, were fabricated after the evaporation of the water at ambient temperature and atmospheric pressure. CNW/PVA composites were dried at $50^{\circ} \mathrm{C}$ for 12 hours and stored in vacuum bags before analysis and testing.

\section{Characterizations}

\section{Chemical component determinations}

Chemical components, including holocellulose content, $\alpha$-cellulose content, Klason lignin content, and ash content were determined for the raw kenaf bast fibers, retted fibers, bleached fibers, microfibers, and CNWs. The ash contents were determined following TAPPI standard T 211-om 93. Klason lignin contents were estimated according to the method of the Institute of Paper Chemistry (1951). Holocellulose is the total carbohydrate fraction (cellulose and hemicellulose) of the fibers, and its content was estimated by the method of Wise et al. (1946). The term $\alpha$-cellulose describes that part of cellulose that does not dissolve in $17.5 \%$ sodium hydroxide solution; it was determined according to the method of German Association of Cellulose Chemists and Engineers (1951).

\section{Morphological analysis}

The samples of retted fibers, bleached fibers, and microfibers were coated with gold to provide electrical conductivity. Scanning electron microscopy (SEM, Zeiss Supra TM 40) was used to analyze fiber morphology using an accelerating voltage of $15 \mathrm{kV}$. Seventy fibers were randomly chosen. Their dimensions were measured using software 
(Smart SEM User Interface). The CNW samples for morphology analysis were obtained by placing a drop of the CNW suspension onto a grid without any staining, and drying it in air at ambient temperature. The dried samples were examined with a transmission electron microscope (TEM, JEOL JEM-2000 EX-II) at an accelerating voltage of $100 \mathrm{kV}$. The dimensions of seventy randomly chosen CNWs were measured from the TEM images.

\section{Functional group analysis}

Fourier Transform Infrared (FTIR) spectra were recorded to analyze the functional groups of the fibers on a Thermo Scientific Nicolet 6700 spectrophotometer.

\section{Crystallinity determination}

The crystallinities of all fiber samples were measured using a Rigaku SmartLab X-ray Diffraction System with an operating voltage of $40 \mathrm{kV}$ and a current of $44 \mathrm{~mA}$. The fiber crystallinities $\left(\chi_{C R}\right)$ were calculated by the Segal method (Segal 1959) as shown in Equation (1).

$$
\chi_{C R}=\left(I_{200}-I_{A M}\right) / I_{200}
$$

Here, $I_{200}$ is the height of the peak between $20^{\circ}$ and $25^{\circ}$, representing both the crystalline and amorphous regions; $I_{A M}$ is the lowest height between $15^{\circ}$ to $22.7^{\circ}$, representing the amorphous regions only.

\section{Tensile properties of CNW/PVA composites}

The CNW/PVA composites with 3\% and 9\% (wt $\%$ ) CNW contents and net PVA film were tested using an Instron 5869 (load cell $50 \mathrm{kN}$ ) universal testing machine in accordance with ASTM D638-08. Composites samples were kept in desiccators for one week before the mechanical testing. Three replicates of each CNW/PVA composites were run. Multiple comparison of the results was conducted with Fisher's Least Square method at $\alpha=0.05$ using SAS 9.2 software (SAS Institute Inc. NC, USA). The fracture surfaces of the samples were observed using scanning electron microscopy (SEM, Zeiss Supra TM 40).

\section{RESULTS AND DISCUSSION}

\section{Yields}

The fiber yields are shown in Table 1.

Table 1. Yields of the Fibers based on the Weight of Raw Kenaf Bast Fiber

\begin{tabular}{|c|c|c|c|c|}
\hline Types of fibers & Retted fiber & Bleached fiber & Microfiber & CNW \\
\hline Yields & $44.6 \%$ & $41.4 \%$ & $26.3 \%$ & $10.4 \%$ \\
\hline
\end{tabular}


Alkaline retting removed most of the lignin and hemicelluloses from the kenaf bast fibers. A fiber yield of $44.6 \%$ (by mass) was obtained after the alkaline retting. The $\alpha$-cellulose content of the raw kenaf bast fibers was determined as $45.95 \%$, which was close to the yield of the retted fibers. This suggested that the components remaining in the fiber after retting were mainly $\alpha$-cellulose, as was verified by the chemical component determination. Bleaching treatment removed the remaining lignin in the retted fibers. Cellulose molecular chains were also cleaved during bleaching. A 41.4\% fiber yield was obtained after bleaching. The bleached fibers were hydrolyzed by the sulfuric acid within the amorphous regions of cellulose molecular chains. The percentage of the crystalline region increased, while the fiber size was reduced by the acid hydrolysis. Some fibers were converted to be individual nanowhiskers, while others were microfibers. The yield of CNWs was $10.4 \%$, while the yield of microfiber was $26.3 \%$. Considering that the $10.4 \%$ CNWs were yielded from $\alpha$-cellulose component, which was $45.95 \%$ from the nontreated fiber (Table 2), it could be estimated that about $22.6 \%$ of $\alpha$-cellulose had been converted into CNWs by the process used here.

\section{Chemical Components of the Fibers}

The holocellulose, $\alpha$-cellulose, Klason lignin, and ash contents of the fibers were shown in Table 2.

Table 2. Chemical Components of the Fibers

\begin{tabular}{|c|c|c|c|c|}
\hline & a-cellulose & Holocellulose & Klason Lignin & Ash \\
\hline Non-treated fiber & $45.95 \%$ & $75.83 \%$ & $19.10 \%$ & $5.07 \%$ \\
\hline Retted fiber & $92.27 \%$ & $94.22 \%$ & $0.24 \%$ & $2.72 \%$ \\
\hline Bleached fiber & $95.19 \%$ & $95.41 \%$ & $0 \%$ & $2.27 \%$ \\
\hline Microfiber & $100 \%$ & $100 \%$ & $0 \%$ & $0 \%$ \\
\hline CNW & $100 \%$ & $100 \%$ & $0 \%$ & $0 \%$ \\
\hline
\end{tabular}

Alkaline retting treatment of the kenaf bast fibers at $160{ }^{\circ} \mathrm{C}$ at the alkaline liquid autogeneous vapor pressure for one hour effectively degraded and dissolved lignin and hemicellulose. The two percentage point difference between the holocellulose content and $\alpha$-cellulose content of retted fiber indicated that a small fraction of hemicellulose remained in retted fibers. If the lignin in retted fibers, although low at $0.24 \%$, had not been removed by bleaching, it would result in acid-insoluble residuals in microfibers and CNWs after acid hydrolysis thus impacting purity. Bleaching removed not only lignin, but also hemicellulose, producing relatively pure cellulosic fibers for the next acid hydrolysis treatment. The hemicellulose content could be estimated from the difference between the holocellulose content and $\alpha$-cellulose content in Table 2. After bleaching, the hemicellulose content was no more than $0.22 \%$, and the klason lignin content was zero. Bhatnagar (2005) reported that the average hemicellulose contents of the flax bast fiber and hemp fiber after acid hydrolysis and alkali treatment were 1 to $2 \%$, and their average lignin content was $3 \%$. The alkali retting and bleaching treatment used in this study were more effective in removing lignin and hemicelluloses. Microfibers and CNWs obtained from acid hydrolysis were pure cellulose fibers. 


\section{Morphology of the Fibers}

The morphology of the raw kenaf bast fiber, retted fiber, bleached fiber, microfiber, and CNW was studied using the SEM or TEM images (Figs. 1 and 2).

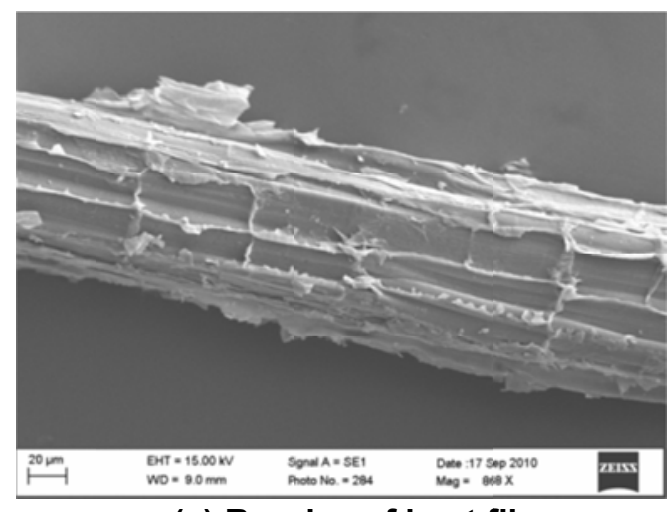

(a) Raw kenaf bast fibers

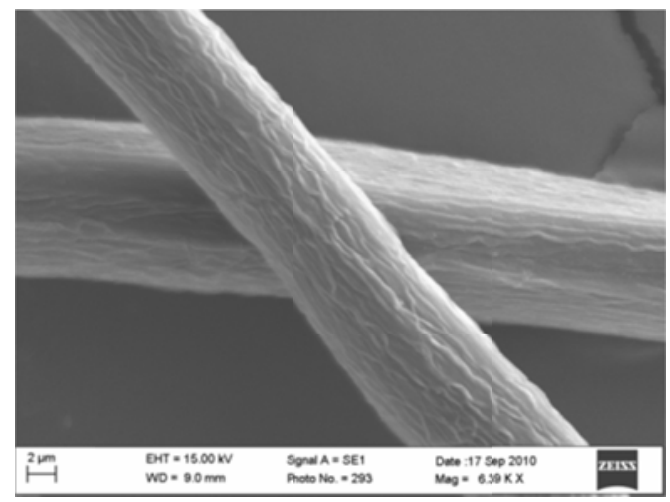

(c) Bleached fibers

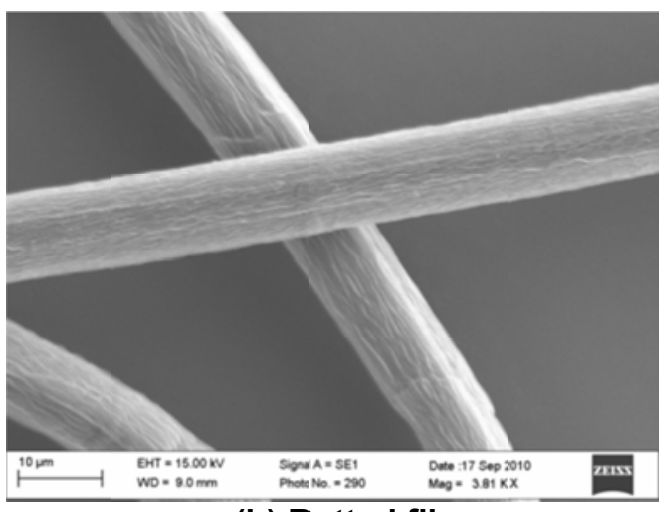

(b) Retted fibers

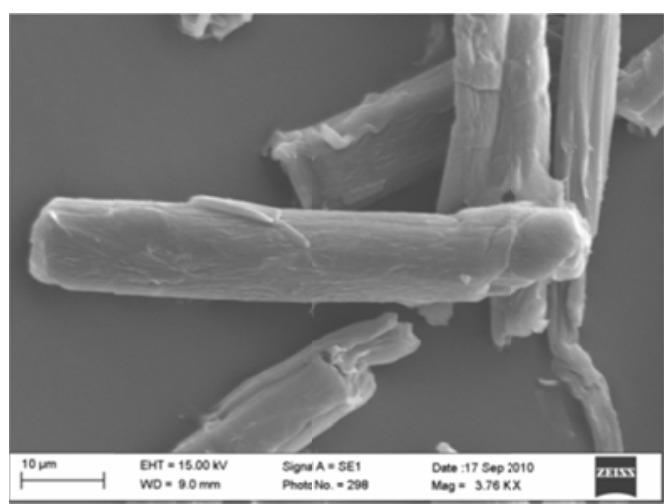

(d) Microfibers

Fig. 1. SEM images of the raw kenaf bast fibers, retted fibers, bleached fibers, and microfibers

The statistics of the fiber lengths and diameters are shown in Table 3.

Table 3. Fiber Length and Diameter Statistics

\begin{tabular}{|c|c|c|c|c|c|}
\hline \multirow{2}{*}{ Length } & Mean & $\begin{array}{c}\text { Retted fibers } \\
(\mu \mathrm{m})\end{array}$ & $\begin{array}{c}\text { Bleached fibers } \\
(\mu \mathrm{m})\end{array}$ & $\begin{array}{c}\text { Microfibers } \\
(\mu \mathrm{m})\end{array}$ & $\begin{array}{c}\text { CNWs } \\
(\mathrm{nm})\end{array}$ \\
\cline { 2 - 6 } & Stdev. & 606.98 & 215.32 & 46.39 & 628.38 \\
\hline \multirow{2}{*}{ Diameter } & Mean & 10.70 & 141.62 & 16.38 & 360.05 \\
\cline { 2 - 6 } & Stdev. & 2.68 & 10.63 & 9.58 & 34.75 \\
\hline
\end{tabular}




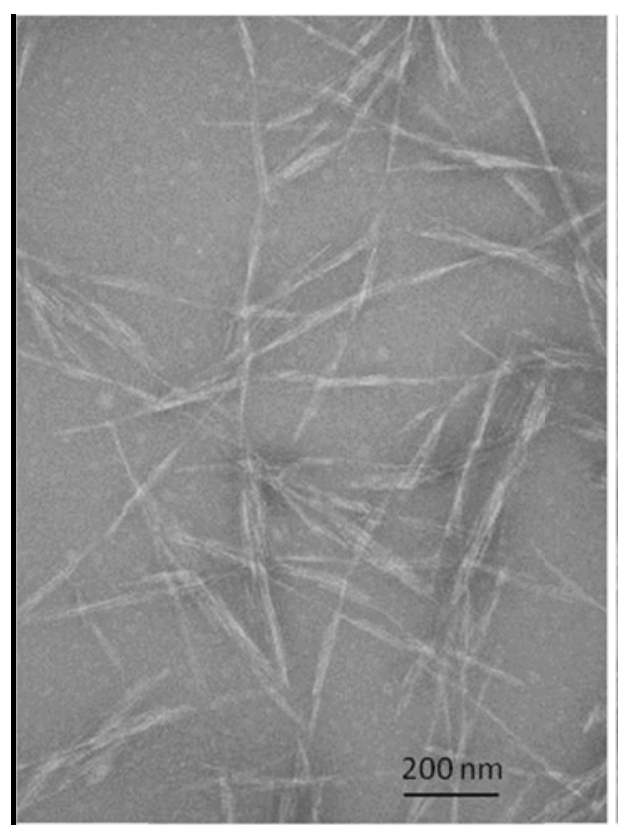

(a)

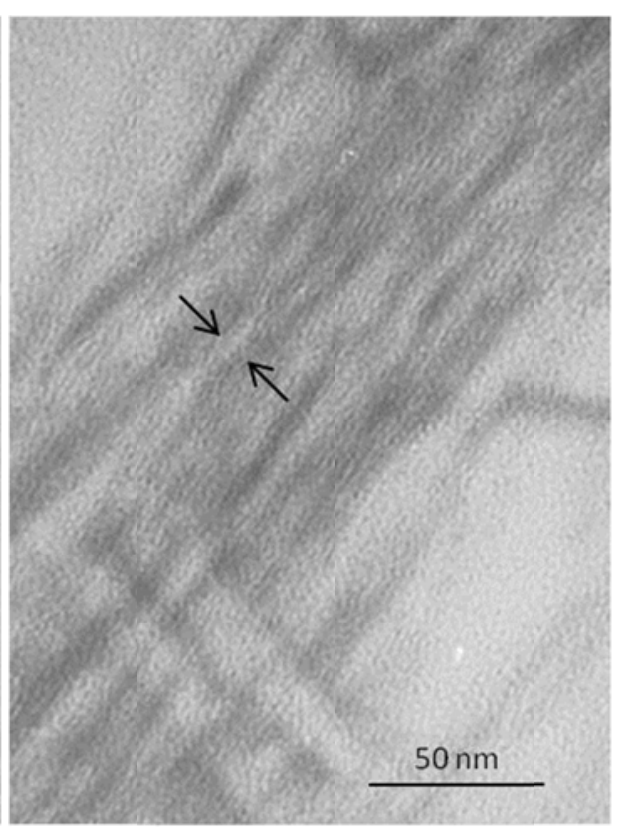

(b)

Fig. 2. TEM images of cellulose nanowhiskers (CNWs). (a) magnification $=50,000 \mathrm{X}$, accelerating voltage $=100 \mathrm{kV}$; (b) magnification $=370,000 \mathrm{X}$, accelerating voltage $=100 \mathrm{kV}$.

The alkaline retting treatment liberated single fibers from the fiber bundles of the raw kenaf bast fibers. The bleached fiber morphology was altered little by the bleaching treatment compared to that of retted fibers. The lengths of retted fibers and bleached fiber had large variations, but their diameters were both approximately $11 \mu \mathrm{m}$. Acidic hydrolysis broke the bleached fibers through their cross sections, thus reducing the fiber lengths significantly. The average aspect ratio of the microfiber was 4.97. Cellulose whiskers, which have nanometer-scaled diameters, were obtained from the acidic hydrolysis treatment. The lengths of the CNWs were in a range from 100 to $1400 \mathrm{~nm}$, and the diameters of the CNWs ranged from 7 to $84 \mathrm{~nm}$. The $\mathrm{CNW}$ aspect ratios were ranged from 10 to 50, and had an average of 18.1. In some related researches, the obtained CNWs had different dimensions. For instance, Roohani (2008) reported that the average length and width were about $172 \mathrm{~nm}$ and $15 \mathrm{~nm}$, respectively, leading to an average aspect ratio of around 11 to 12 . The diameter of the needle-like MCC nanocellulose prepared by Lee (2009) was around $100 \mathrm{~nm}$. The cellulose nanofibers prepared from flax fiber by Qua (2009) showed a diameter of around $9 \mathrm{~nm}$, a length of around $141 \mathrm{~nm}$, and an average aspect ratio of 16.6. The differences in fiber dimensions from different studies may be due to the different fiber resources and treatment methods.

Individual CNWs were composed of several parallel aligned crystallites. These can be observed in Fig. 2 between the two arrows. The width of a crystallite measured about $5.4 \mathrm{~nm}$. The dimensions of the monoclinic unit cell of the regenerated cellulose were reported (Nugmanov et al. 1987) as $\mathrm{a}=0.814 \mathrm{~nm}, \mathrm{~b}=0.919 \mathrm{~nm}$, and $\mathrm{c}=1.03 \mathrm{~nm}$ (fiber axis). The widths of the CNWs were obtained in a range from seven to $84 \mathrm{~nm}$, while the lengths were from 100 to $1400 \mathrm{~nm}$. Therefore, an individual CNW was composed of 100 to 1300 unit cells aligned in the direction of the fiber axis (c). A cross section of an individual CNW consisted of eight to 103 unit cells, or, one to 15 crystallites. 


\section{Fourier Transform Infrared (FT-IR) Spectroscopy}

In Fig. 3, the FT-IR spectra show the functional groups on the fiber surfaces and within detectable regions below the fiber surfaces.

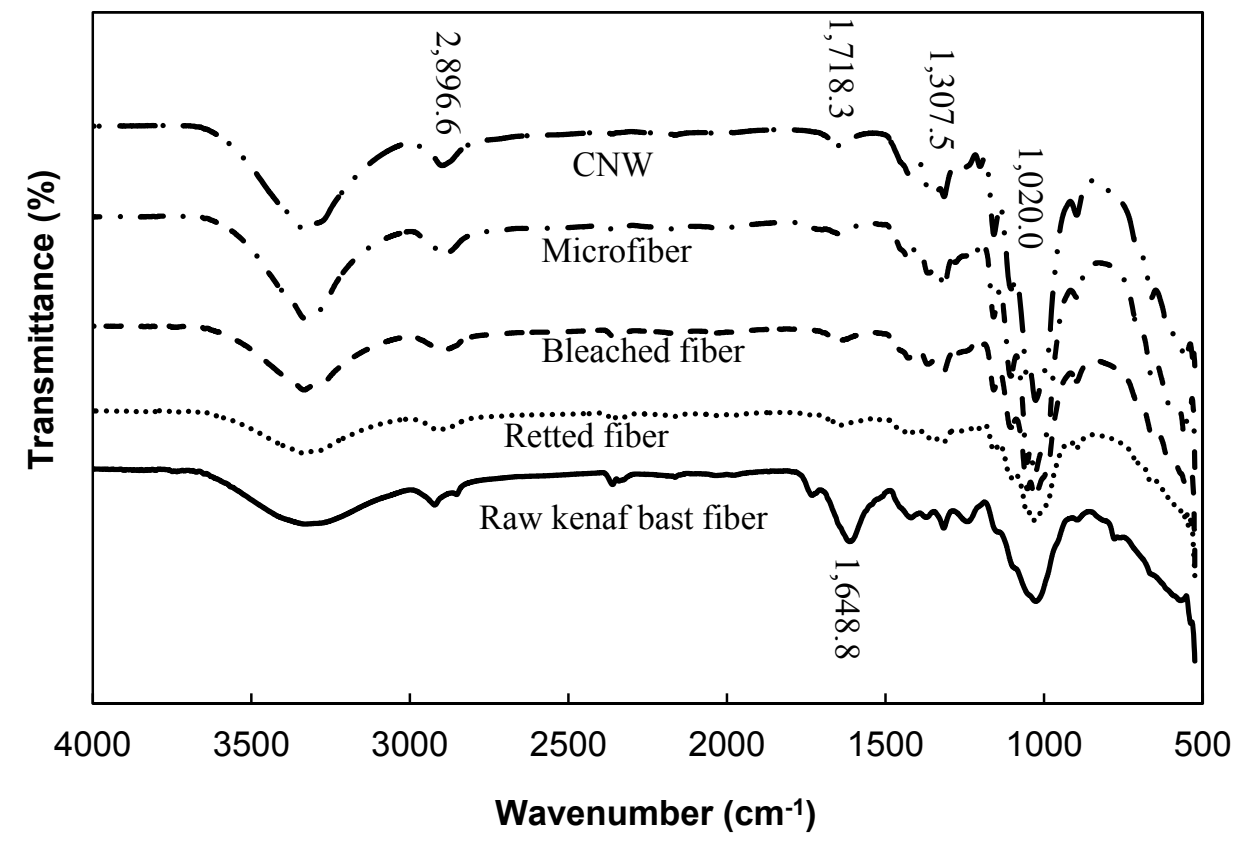

Fig. 3. FT-IR spectra of the fibers

Hydroxyl stretching vibrations are found between $3000 \mathrm{~cm}^{-1}$ and $3500 \mathrm{~cm}^{-1}$. Clearly, a highly hydrogen bonded network exists, as indicated by the lower frequencies, with some free hydroxyls at high frequencies. The intensity of this peak envelope increased gradually going from untreated fiber, retted fiber, bleached fiber, microfiber, to nanofiber because the specific surface area of the fibers increased. More hydroxyl groups in the surface and in the detectable regions below the surface are exposed as the fiber size is reduced from the macro to the nano scales. The peaks at $2896.6 \mathrm{~cm}^{-1}, 1718.3 \mathrm{~cm}^{-1}$, $1307.5 \mathrm{~cm}^{-1}$, and $1020 \mathrm{~cm}^{-1}$ represent the $\mathrm{C}-\mathrm{H}, \mathrm{C}=\mathrm{O}, \mathrm{C}-\mathrm{O}$, and $\mathrm{C}-\mathrm{C}$ stretching, respectively. The peak at $1648.8 \mathrm{~cm}^{-1}(\mathrm{C}=\mathrm{C}$ stretching $)$ found in untreated kenaf bast fibers disappeared in all the treated fibers. This corresponds to the removal of carboncarbon unsaturation present in lignin components and extractives.

\section{Crystallinity}

The X-ray diffraction spectra of the fibers are shown in Fig. 4. The calculated degrees of fiber crystallinity of the fibers are shown in Table 4 . The fiber crystallinities gradually increased at each stage of the process. Alkaline retting removes lignin and hemicelluloses, so that the percentage of the crystalline regions in cellulose increased. Hydrogen peroxide bleaching accelerated the cleavage of the cellulose molecular chains within the amorphous regions, resulting in the further increase of the crystallinity of the bleached fibers. In addition, the remaining lignin was degraded by hydrogen peroxide and removed during bleaching. Acid hydrolysis improved the crystallinity of the fibers significantly by the cleavage of glycosidic bonds in cellulose molecular chains within 
amorphous regions. Therefore, the relative amounts of amorphous regions were greatly diminished. However, the crystalline regions were highly resistant to acid hydrolysis.

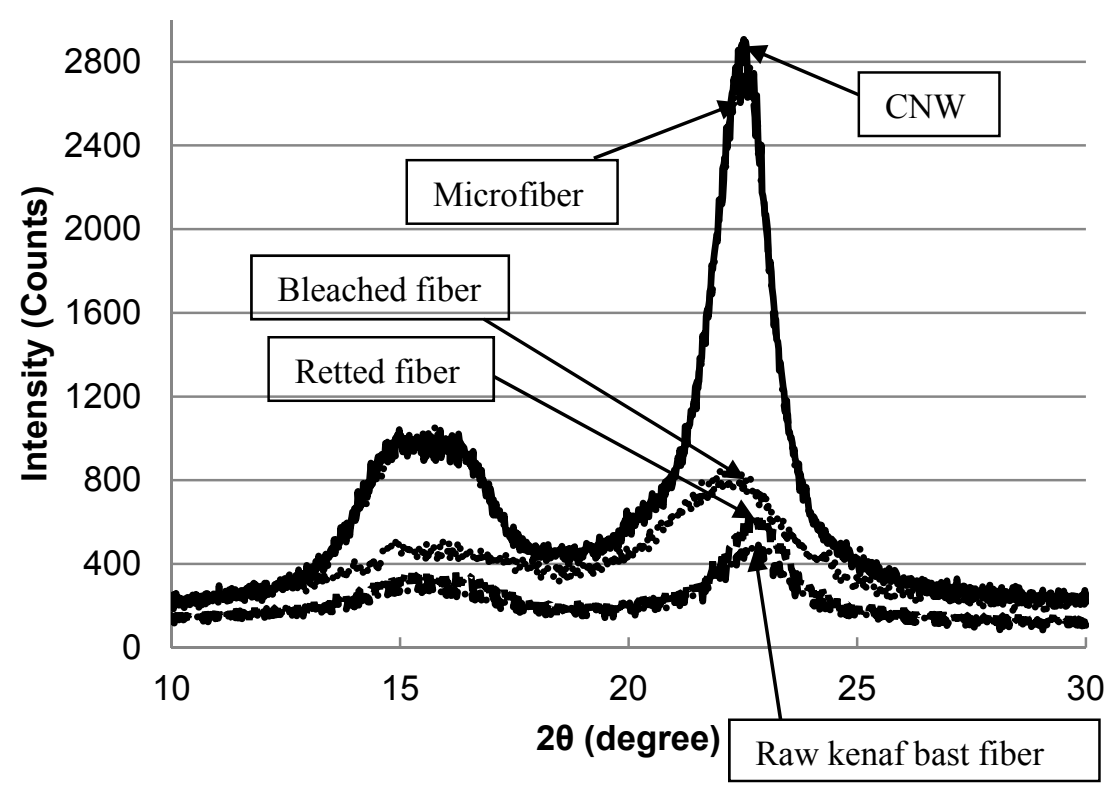

Fig. 4. X-ray diffraction spectra of the fibers

Table 4. Fiber Crystallinities

\begin{tabular}{|c|c|c|c|c|c|}
\hline Types of fibers & Raw kenaf bast fiber & Retted fiber & Bleached fiber & Microfiber & CNW \\
\hline Crystallinities & $49.9 \%$ & $63.8 \%$ & $68.9 \%$ & $83.5 \%$ & $83.9 \%$ \\
\hline
\end{tabular}

\section{Tensile Strengths of CNW/PVA Composites}

The tensile strengths of the CNW/PVA composites are shown in Fig. 5. The SEM images of the fracture surface of the samples are shown in Fig. 6.

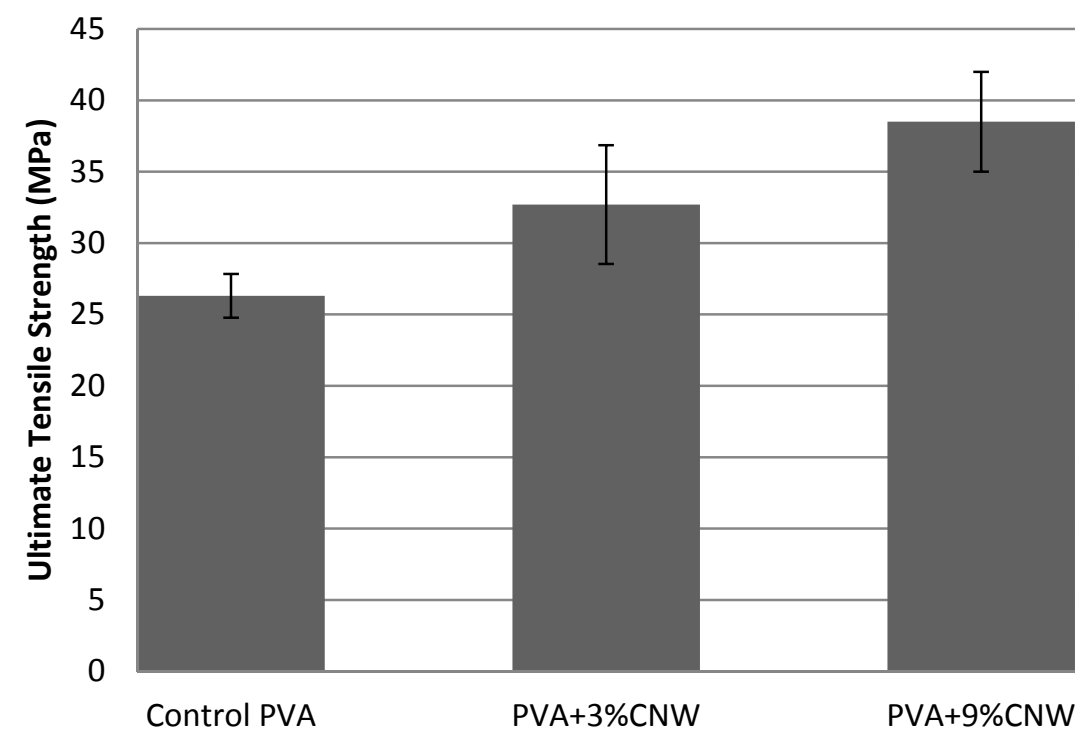

Fig. 5. Tensile strength of the CNW/PVA composites 


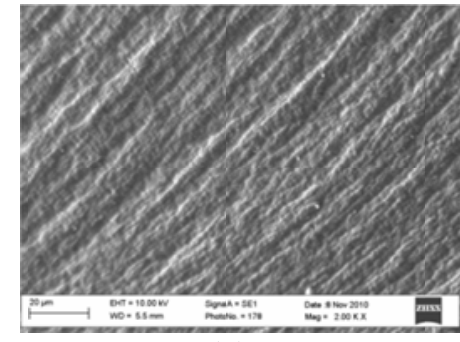

(a)

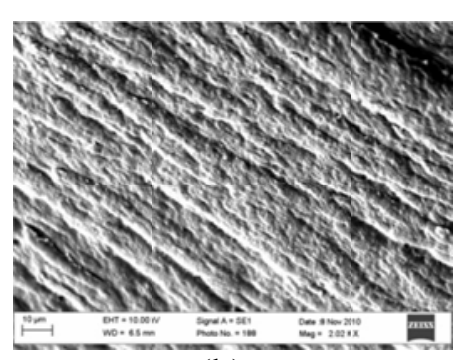

(b)

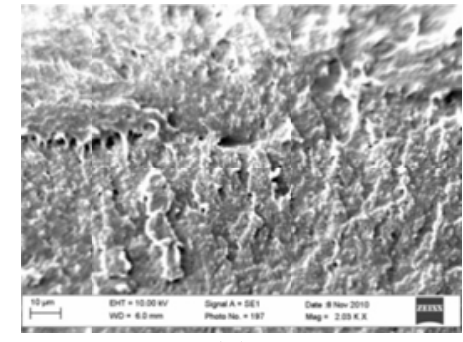

(c)

Fig. 6. SEM images of fracture surfaces of the composites. (a) is the pure PVA; (b) is the PVA/CNW composites with $3 \% \mathrm{CNW}$; (c) is PVA/CNW composites with $9 \% \mathrm{CNW}$

The tensile strength of the composites increased as the CNW content was raised from $0 \%$ to $9 \%$. The tensile strength of the PVA composites was improved by $46.2 \%$ when $9 \% \mathrm{CNW}$ s was incorporated. The SEM images of the fracture surfaces suggested that cracks were formed in $\mathrm{CNW} / \mathrm{PVA}$ composites before failure. Few cracks were generated in pure PVA. But the most amounts of cracks grew in CNW/PVA composites that were fabricated with $9 \% \mathrm{CNW}$. The cracks are consistent with high energy absorption. This is the reason why the CNW/PVA composites $(9 \% \mathrm{CNW})$ obtained the highest tensile strength. The cracks resulted from high inter-laminar shear strength between CNW and PVA. The high inter-laminar shear strength may be due to the hydrogen bonds between $\mathrm{CNW}$ and PVA. Statistical analysis showed that the average tensile strengths of the CNW/PVA composites fabricated with $3 \% \mathrm{CNW}$ and $9 \% \mathrm{CNW}$ were different at 95\% significance level, and the tensile strength of the CNW/PVA composites fabricated with $3 \% \mathrm{CNW}$ was significantly different from that of pure PVA at $95 \%$ significance level. The tensile strength of the composites increased by $24.2 \%$ when $3 \%$ CNW reinforced PVA, and by $46.4 \%$ when $9 \% \mathrm{CNW}$ was employed. Bhatnagar (2005) indicated that the cellulose nanofibers prepared from different resources, such as hemp, rutabage, flax, and kraft pulp, would present different reinforcement. The CNWs prepared form kenaf bast fiber in this study had a greater contribution in tensile strength of the PVA composites than those from flax bast fiber in Bhatnagar's (2005) study (10.2\% improvement with $10 \mathrm{wt}$ \% cellulose nanofiber addition in PVA composites). However, the CNWs from kenaf bast fiber provided less reinforcement than those from rutabage and hemp. Lee (2009) reported that $1 \mathrm{wt} . \%$ loading of nanocellulose resulted in a significant increase of tensile strength, but when the nanocellulose loading was increased to 3 and 5 wt.\% to the PVA matrix, the tensile strength graduately decreased. However, Qua (2009) showed that 5 wt.\% MCC nanofiber addition in PVA composites only improved the tensile strength by $2 \%$. The discrepancy in these results may be due to the differences in the fiber characteristics, such as the aspect ratio, crystallinity, morphology, etc.

\section{CONCLUSIONS}

1. Pure cellulose fibers from the micrometer scale to the nanometer scale were obtained by means of all-chemical processes. 
2. Approximately $22.6 \%$ of the $\alpha$-cellulose in the raw kenaf bast fibers could be converted into crystalline nanowhiskers (CNWs).

3. The fiber crystallinity increased at each stage of the chemical processes. A high crystallinity of CNW, $83.9 \%$, was obtained.

4. The $\mathrm{CNW}$ s endowed the CNW/PVA composites with a significantly improved tensile strength of $46.2 \%$ when only $9 \%$ (wt $\%$ ) CNWs were incorporated.

\section{ACKNOWLEDGMENTS}

The project was supported by Department of Energy (DOE), fund \# 362000060803 through the Center of Advanced Vehicular System (CAVs) at MSU. Acknowledgment should be given to Dr. Sangyeob Lee, a previous post-doctoral research scientist in the composites research group, Dr. El Barbary M. Hassan, Bio-oil Group, Mr. William A. Monroe and Ms. Amanda Lawrence, Research Associates in Electron Microscope Center (EM Center), Mississippi State University (MSU), Dr. Giselle Thibaudeau, Director of the EM Center, Prof. Dr. Mark Horstemeyer, professor in the Mechanical Engineering Department at MSU, and Mr. Stephen Horstemeyer, Laboratory Manager at CAVs, for their support and help.

\section{REFERENCES CITED}

Bhatnagar, A., and Sain, M. (2005). "Processing of cellulose nanofiber-reinforced composites," Journal of Reinforced Plastics and Composites 24 (12),1259-1268.

Chakraborty, A., Sain, M., and Kortschot, M. (2005). "Cellulose microfibrils: A novel method of preparation using high shear refining and cryocrushing," Holzforschung 59(1), 102-107.

German Association of Cellulose Chemists and Engineers. (1951). "Bestimmung der Alphacellulose und de langeunloslichen Anteils von Zellstoffen," Markblatt IV/29 Zellcheming.

Henriksson, M., Henriksson, G., Berglund, L. A., and Lindström, T. (2007). "An environmentally friendly method for enzyme-assisted preparation of microfibrillated cellulose (MFC) nanofibers," European Polymer Journal 43(8), 3434-3441.

Iwamoto, S., Nakagaito, A. N., Yano, H., and Nogi, M. (2005). "Optically transparent composites reinforced with plant fiber-based nanofibers," Applied Physic A: Materials Science \& Processing 81(6), 1109-1112.

Lee, S. Y., Mohan, D. J., Kang, I. A., Doh, G. H., Lee, S., and Han, S. H. (2009). "Nanocellulose reinforced PVA composite films: Effects of acid treatment and filler loading," Fibers and Polymers 10(1), 77-82.

Lu, J., Wang, T., and Drzal, L. T. (2008). "Preparation and properties of microfibrillated cellulose polyvinyl alcohol composite materials," Composites: Part A 39, 738-746.

Nugmanov, O. K., Pertsin, A. I., Zabelin, L. V., and Marchenko, G. N. (1987). "The molecular-crystal structure of cellulose," Russian Chemical Reviews 56(8), 764-776. 
Qua, E. H., Hornsby, P. R., Sharma, H. S. S., Lyons, G., and McCall, R. D. (2009).

"Preparation and characterization of poly(vinyl alcohol) nanocomposites made from cellulose nanofibers," Journal of Applied Polymer Science 113, 2238-2247.

Roohani, M., Habibi, Y., Belgacem, N. M., Ebrahim, G., Karimi, A. N., and Dufresne A. (2008). "Cellulose whiskers reinforced polyvinyl alcohol copolymers nanocomposites," European Polymer Journal 44, 2489-2498.

Segal, L. (1959). "An empirical method for estimating the degree of crystallinity of native cellulose using the X-ray diffractometer," Textile Research Journal 29(10), 786-794.

Siqueira, G., Bras, J., and Dufresne, A. (2009). "Cellulose whiskers versus microfibrils: Influence of the nature of the nanoparticle and its surface functionalization on the thermal and mechanical properties of nanocomposites," Biomacromolecules 10(2), 425-432.

The Institute of Paper Chemistry (1951). Method No. 428. The Institute of Paper Chemistry, Appleton, Wisconsin.

Tsuchida, T., and Yoshinaga, F. (1997). "Production of bacterial cellulose by agitation culture systems," Pure and Applied Chemistry 69(11), 2453-2458.

Wang, S., Cheng, Q., Rials, T. G., and Lee, S. H. (2006). "Cellulose microfibril/ nanofibril and its nanocompsites," Proceedings of the 8th Pacific Rim Bio-based Composites Symposium. Nov. 20-23, 301-308.

Wise, L. E., Murphy, M. and D'Addieco A. (1946). "Chlorite holocellulose, its fractionation and bearing on summative wood analysis and on studies on the hemicelluloses," Paper Trade Journal 122(2), 35-43.

Zadorecki, P. J., and Michell, A. J. (1989). "Future prospects for wood cellulose as reinforcement in organic polymer composites," Polymer Composites 10(2), 69-77.

Article submitted: December 4, 2010; Peer review completed: January 15, 2011; Revised version received and accepted: January 25, 2011; Published: January 26, 2011. 